\title{
The Potential of Airborne Hyperspectral Images to Detect Leaf Nitrogen Content in Potato Fields
}

\author{
Feng Li \\ Shandong Provincial Climate Center, Jinan, China \\ Lfeng1029@163.com
}

\author{
Victor Alchanatis \\ Volcani Center, Bet-Dagan, Israel \\ Victor@volceni.agr.gov.il
}

\begin{abstract}
Leaf nitrogen (leaf $\mathrm{N}$ ) status is important, to optimize nitrogen management and improve yield quantity and quality. Relationships between canopy spectral reflectance at 400-1000 $\mathrm{nm}$ with ASIA and nitrogen levels in potato leaves were studied. Five nitrogen $(\mathrm{N})$ fertilizer treatments in 2007 and seven nitrogen $(\mathrm{N})$ fertilizer treatments in 2008 were applied to build up levels of nitrogen variation in potato fields in Israel. The leaves were sampled and analyzed for leaf $\mathbf{N}$.

Prediction models of leaf $\mathrm{N}$ were developed based on an optical index named transformed chlorophyll absorption reflectance index (TCARI) and on the ratio TCARI/OSAVI (the optimized soil adjusted vegetation index) for airborne hyperspectral images of 2007 and 2008. The ratio TCARI/OSAVI resulted in stronger correlations than TCARI with leaf $\mathbf{N}$ for canopy spectral reflectance.
\end{abstract}

The best estimation models from the ratio TCARI/OSAVI were applied to all the potato pixels of the airborne images. The values of the leaf $\mathrm{N}$ distribution map ranged from $3.0 \%$ to $6.6 \%$, which was quite consistent with those of laboratory measurements from $3.6 \%$ to $5.9 \%$. The results show the potential of using information extracted from airborne hyperspectral images for distinguishing spatial variability in leaf $\mathbf{N}$ status in potato fields.

Keywords-Airborne hyperspectra limage; Transformed chloro-phyll absorption reflectance index (TCARI); Optimized soil adjusted vegetation index (OSAVI); Nitrogen; Potato

\section{INTRODUCTION}

Potato (Solanum tuberosum L.) is an important crop worldwide, with total world production of about 360 million metric ton[1]. Potato yield and quality are very dependent on an adequate supply of nitrogen [2,3]. The relatively shallow root system of the potato crop, coupled with its large nitrogen $(\mathrm{N})$ requirement and sensitivity to water stress on coarse textured soil increases the risk of nitrate $\left(\mathrm{NO}_{3}-\mathrm{N}\right)$ leaching. Therefore, precise $\mathrm{N}$ management for potato is important, both for maximizing production and for minimizing $\mathrm{N}$ loss to groundwater. Therefore, with this dilemma, efficient monitoring of plant $\mathrm{N}$ status and appropriate $\mathrm{N}$ fertilizer management are essential to balance the increasing cost of $\mathrm{N}$ fertilizer, demand by the crop, and the need to minimize environmental damage, especially water quality.

Remote sensing techniques can indicate crop $\mathrm{N}$ status [4-8]. Light reflected by vegetation in the visible region of the spectrum is predominantly influenced by chlorophyll pigments in the leaf tissues, and these relate to the leaf $\mathrm{N}$ concentration [9]. Chlorophyll absorbs light in the red ( $670 \mathrm{~nm})$ and blue $(\sim 450 \mathrm{~nm})$ portions of the spectrum [10], thereby providing diagnostic absorption features. In addition, near-infrared (NIR) reflectance is influenced by the internal structure of the leaf cell; well hydrated, healthy, spongy mesophyll cells reflect infrared wavelengths strongly[10]. The spectral region between the red absorption feature and the region of high NIR reflectance, termed the 'red-edge', changes shape and position when the plant becomes deficiencient in $\mathrm{N}$ [11]. Therefore, measurements of reflected energy from crop leaves and canopies can be used to estimate chlorophyll concentration rapidly and provide a measure of $\mathrm{N}$ content $[9,11,12]$.

The use of hyperspectral images, validated by airborne hyperspectral sensors, can be used to address both spatial and temporal variability in leaf $\mathrm{N}$ content to improve mid-season $\mathrm{N}$ management. A compact airborne spectrographic imager was used successfully to estimate chlorophyll content and to discriminate between $\mathrm{N}$ treatments in corn fields and forests. [9,12]. Chen et al. assessed the efficiency of crop nitrogen treatment in corn and wheat via spectral indicator using airborne hyperspectral images[12]. Ryu et al. also evaluated a nitrogen content prediction model using airborne hyperspectral remote sensing at panicle nitiation stage via a multiple linear regression [13]. The nitrogen content prediction models at panicle initiation stage were also estimated via PLSR by Ryu et al.[14]. These studies have demonstrated the potential of using airborne hyperspectral data in the Visible and NIR regions to detect the efficiency of chlorophyll and nitrogen content. The present research of estimating the leaf $\mathrm{N}$ for potato are seldom with hyperspectral images, especially using the airborne HS images $[15,16]$.

In this study, the airborne hyperspectral images were applied to analyze the leaf nitrogen content of potato using two years data. The objectives of this research were:

(1) to establish a leaf nitrogen content prediction model via TCARI and the ratio TCARI/OSAVI;

(2) to compare with the two models and find the best model for mapping the distribution of leaf $\mathrm{N}$ levels in potato fields.

\section{MATERIALS AND METHODS}

\section{A. Experimental Field and Management}

The study was conducted in the spring growing seasons of 2007 and 2008 on two commercial potato fields planted with cv. Desiree in Kibbutz Ruhama, Israel $\left(31.38^{\circ} \mathrm{N}\right.$, 
$34.59^{\circ} \mathrm{E}$ ). This agricultural land is on the southern part of Israel's coastal plain, on the boundary between Mediterranean and semi-arid climates. The soil texture of both fields is sandy loam. The plots were planted at the beginning of February and harvested in mid-June. Average temperature during this period was between $15^{\circ} \mathrm{C}$ (February) and $35^{\circ} \mathrm{C}$ (June). Average annual rainfall during the spring season in this region is only about $100 \mathrm{~mm}$, therefore the fields were irrigated. In both 2007 and 2008 growing seasons the plots received the same applications of pre-season compost $\left(30 \mathrm{~kg} \mathrm{ha}^{-1}\right)$, phosphate $\left(180 \mathrm{~kg} \mathrm{ha}^{-1}\right)$ and KCL (180kg ha $\left.{ }^{-1}\right)$.

To enable the recognition and analysis of the sub-plots in airborne hyperspectral images, big plots were built. In 2007, an area of 8 ha was divided into sub-plots of $18 \times$ 50-100m. In 2008, an area of 5ha was divided into sub-plots of $18 \times 40-80 \mathrm{~m}$. The treatments in both seasons included commercial treatment (fertigation) with $\mathrm{N}$ (supplied as urea) at $400 \mathrm{~kg} \mathrm{~N} \mathrm{ha}^{-1}$. In the two years five rates of $\mathrm{N}$ were applied, 0, 100, 200, 300 and 400kg N ha ${ }^{-1}$. In both years the reduced $\mathrm{N}$ treatments were applied as a slow release coated urea granular fertilizer (Multigro 43-0-0 SRN, Haifa Chemicals Inc., Haifa, Israel) at a single application before planting (Tables 1 and 2).

TABLE I. NITROGEN TREATMENTS APPLIED IN THE POTATO FIELD IN SPRING 2007

\begin{tabular}{|c|c|c|c|}
\hline Nitrogen treatment & N rate $\left(\mathrm{kg} \mathrm{ha}^{-1}\right)$ & Percentage $\mathrm{N}$ rate relative to commercial rate & Application type \\
\hline T4 & 400 & 100 & Commercial(urea); fertigation \\
\hline T3 & 300 & 75 & Multigro® 43-0-0 SRN; base \\
\hline T2 & 200 & 50 & Multigro® 43-0-0 SRN; base \\
\hline T1 & 100 & 25 & Multigro® 43-0-0 SRN; base \\
\hline T0 & 0 & 0 & Base \\
\hline
\end{tabular}

TABLE II. NITROGEN TREATMENTS APPLIED IN THE POTATO FIELD IN SPRING 2008

\begin{tabular}{|c|c|c|c|}
\hline Nitrogen treatment & $\mathrm{N}_{\text {rate }}\left(\mathrm{kg} \mathrm{ha}^{-1}\right)$ & Percentage N rate relative to commercial rate & Application type \\
\hline T6 & 400 & 100 & Multigro® 43-0-0 SRN; base \\
\hline T5 & 400 & 100 & Commercial(urea); fertigation \\
\hline T4 & 300 & 75 & Multigro® 43-0-0 SRN; base \\
\hline T3 & 200 & 50 & Multigro® 43-0-0 SRN; base \\
\hline T2 & 100 & 25 & Multigro® 43-0-0 SRN; base \\
\hline T1 & 0 & 0 & Base \\
\hline T0 & 0 & 0 & NONE \\
\hline
\end{tabular}

\section{B. Measurement of Vegetation Data}

Each year, after the images were obtained, the vegetation data consisting of the petiole $\mathrm{NO}_{3}-\mathrm{N}$ and leaf $\mathrm{N}$ of the leaves, was quantified. Vegetation data were sampled at 10 plots with two zero plots in 2007, 26 plots with eight zero plots in 2008. At each plot, in 2007, there were five sampling points; in 2008, there were two sampling points. Collecting the leaf samples after spectrum measurement, put them in ice bucket with freshness protection package as soon as possible. All sub-samples were dried 30 mins in a circulation oven drier at $105^{\circ} \mathrm{C}$, then cooled down to $65^{\circ} \mathrm{C}$ and maintained about 1 hour. The samples of drying were measured the leaf nitrogen content using Kjeldahl method [17]. Finally, the mean of the sub-samples were calculated as the nitrogen content of each plot.

\section{Airborne Hyperspectral Image Acquisition}

Airborne hyperspectral images were acquired with AISA Eagle (Spectral Image, Spectral Imaging Ltd., Oulu, Finland) three days in 2007 and three days in 2008. The image acquisition system is a complete pushbroom system, consisting of a HS sensor head, a miniature GPS/INS sensor, and a data acquisition unit in a rugged $\mathrm{PC}$ with a display unit and power supply. It has a 1,000 pixel swath width and was configured to capture imagery in 420 narrow bands (2-3 nm spectral resolution) covering the visible and near-infrared portions of the solar spectrum from 398 to
$1000 \mathrm{~nm}$; the images were taken at an altitude of approximately $1000 \mathrm{~m}$. The ground spatial resolution was $0.5 \mathrm{~m}$.

\section{Airborne Hyperspectral Image Processing}

The images were analysed using the Environment for Visualizing Images software, ENVI version 4.3, ITT Visual Information Solutions, Boulder, USA. Reflectance panels were set on the sides of the field to compensate for the differences in the amount of sunlight for each measurement. Raw airborne data was first pre-processed in several steps, in order to enable analysis and interpretation. Radiometric corrections were applied to all raw data. Following radiometric correction, the data was converted into reflectance via the "Empirical Line" method using the reflectance of the reference panels. The average reflectance of each plot was calculated from the inner part of the plot, in order to exclude the reflectance of boundary for the targeted plot and surrounding plots.

\section{E. Airborne Hyperspectral Data Analysis}

Prediction models of $\mathrm{N}$ levels were developed by two methods:

(1) Calculation of the transformed chlorophyll absorption reflectance index (TCARI),

(2) Calculation of the ratio of TCARI/OSAVI.

Many vegetation indices (VIs) have been developed to estimate crop biophysical parameters and various stress. 
These indices, can be grouped into two categories, namely, chlorophyll related indices such as the chlorophyll vegetation index (CVI) and the CARI family; and the red edge indices which are essentially a ratio between reflectance of two bands in the red-edge range such as the ratio 740 and 720 ( $\rho 740: \rho 720)$. From proposed indices in the literature [11], TCARI was shown to be an effective leaf chlorophyll estimator [16]. Therefore, we selected TCARI to repesent the VI approach in this study. The equation for TCARI introduced by Haboudane et al., [9]is given by

$$
\text { TCARI }=3\left[(\rho 700-\rho 670)-0.2(\rho 700-\rho 550)\left(\frac{\rho 700}{\rho 670}\right)\right],
$$

where $\rho$ is the reflectance value of the corresponding wavelength. The TCARI is a modification of the modified chlorophyll absorption reflectance index (MCARI) that was developed by Daughtry et al., [2]:

$$
\operatorname{MCARI}=[(\rho 700-\rho 670)-0.2(\rho 700-\rho 550)]\left(\frac{\rho 700}{\rho 670}\right) .
$$

According to Gitelson and Merzlyak[6] wavelengths in the range $530-630 \mathrm{~nm}$ and of $700 \mathrm{~nm}$ are sensitive to the chlorophyll content in plant leaves. The $550 \mathrm{~nm}$ band matches the minimum chlorophyll absorption in the visible region[9]; therefore the MCARI comprises one chlorophyll absorption band at $670 \mathrm{~nm}$ and two chlorophyll-sensitive bands at 550 and $700 \mathrm{~nm}$. The TCARI is calculated from the same bands as the MCARI, but the ratio between the reflectance at 700 and $670 \mathrm{~nm}$ is used to filter the background reflectance at 700 and $550 \mathrm{~nm}$. To differentiate further between LAI and chlorophyll sensitivity proposed the ratio of TCARI/OSAVI, where the optimized soil adjusted vegetation index (OSAVI) is introduced to minimize the sensitivity to differences in the canopy LAI:

$$
\frac{\text { TCARI }}{\text { OSAVI }}=\frac{3\left[\left(\rho_{700}-\rho_{670}\right)-0.2\left(\rho_{700}-\rho_{550}\right) \frac{\rho_{700}}{\rho_{670}}\right]}{\frac{1.16\left(\rho_{800}-\rho_{670}\right)}{\rho_{800}+\rho_{670}+0.16}} .
$$

Hu et al., [9] predicted chlorophyll content successfully from airborne sensor measurements by applying the TCARI/OSAVI ratio to corn, soybean and wheat fields. Zarco-Tejada et al., compared chlorophyll estimates of vines obtained with TCARI and with TCARI/OSAVI; They found TCARI advantageous for pure vegetation data and TCARI/OSAVI for mixed soil and vegetation data[18]. It showed that TCARI/OSAVI and the CVI resulted in stronger correlations with chlorophyll concentration in the canopy level than those for the red-edge based indices.

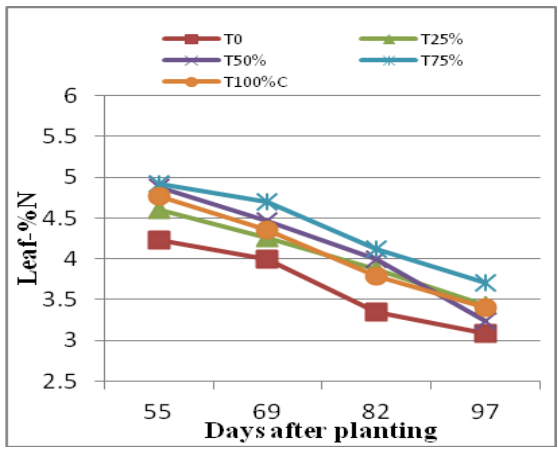

(a)

\section{RESUlTS AND DisCUSSIONS}

\section{A. Temporal Changes in Leaf $N$ Levels}

Leaf $\mathrm{N}$ content decreased during the growing season for all fertilizer treatments for the 2007 data (Fig. 1a).

The 2008 data (Fig. 1b) show that similar temporal changes occurred, but with a few differences. The leaf $\mathrm{N}$ content values of $\mathrm{T} 100 \% \mathrm{C}, \mathrm{T} 100 \%$ at the second measurement increased compared with the fisrt field measurement, and $\mathrm{T} 25 \%$, T50\% also increased at the third measurement compared with the second field measurement, the others decrease during the growing season. Not the higher nitrogen levels, there would be higher value of the leaf $\mathrm{N}$.

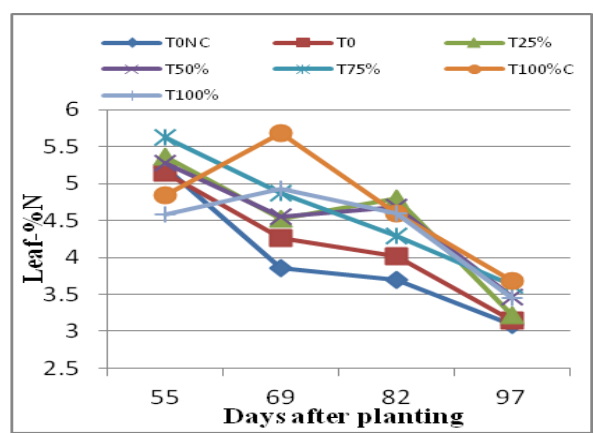

(b)

Figure 1. Leaf $\mathrm{N}$ content of potatoes from five $\mathrm{N}$ treatments for the growth period in: a 2007 and b 2008 


\section{B. Relationships between TCARI, TCARI/OSAVI and N Levels}

The TCARI and TCARI/OSAVI values were calculated from airborne hyperspectral images of 2007 and 2008. Leaf $\mathrm{N}$, TCARI and TCARI/OSAVI values were averaged among the same treatment for all replicates for AISA airborne hyperspectral data. It was observed that the correlation between TCARI and leaf $\mathrm{N}$ decreased, this was due to the TCARI was easily affected by the background reflectance and LAI of crop.

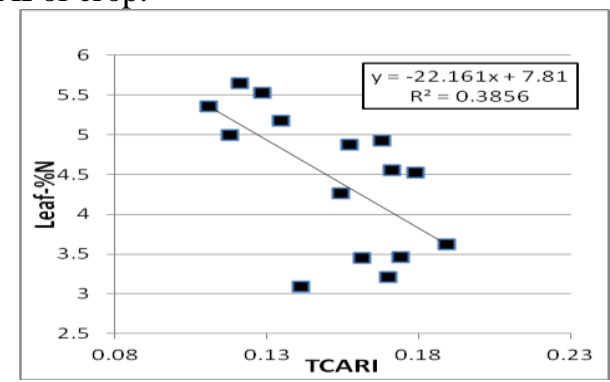

(a)
The correlation between TCARI/OSAVI and leaf $\mathrm{N}$ were much stronger negative linear than that of TCARI for 2007 and 2008 airborne hyperspectral data, as shown in Fig. 2 (a-b) and Fig. 3 (a-b)

The ratio TCARI/OSAVI thus represented a spectral predictor of pigment concentrations at the canopy scales, which minimized the perturbing effects of background reflectance and LAI variability. It showed a high correlation with leaf $\mathrm{N}$ and offers a greater potential for estimating potato leaf $\mathrm{N}$.

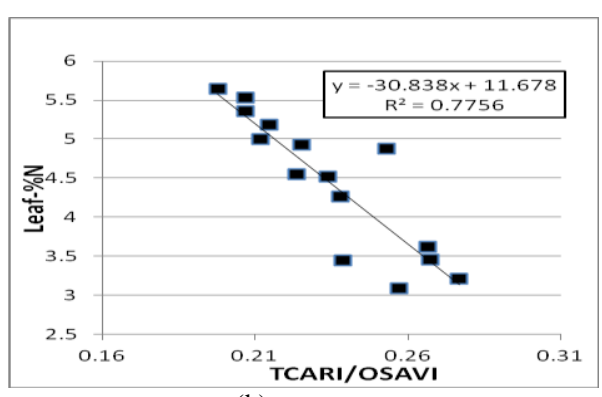

(b)

Figure 2. Leaf $\mathrm{N}$ as a function of TCARI values (a) ; TCARI/OSAVI values (b) in 2007 using AISA data

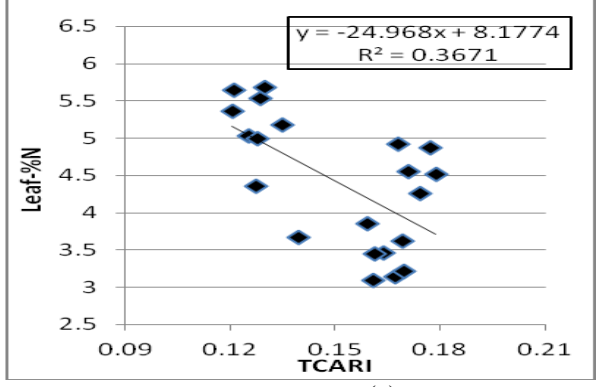

(a)

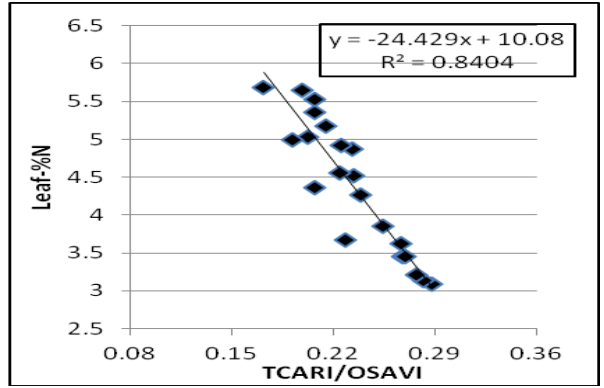

(b)

Figure 3. Leaf $\mathrm{N}$ as a function of TCARI values (a) ; TCARI/OSAVI values (b) in 2008 using AISA data

\section{Mapping the Distribution of N Levels Using AISA Airborne Hyperspectral Data}

Airborne image from April 11, 2008 was used to map the spatial distribution of leaf $\mathrm{N}$ status over large areas of potato crops, using the best developed models based on the ratio TCARI/OSAVI from 2008. The leaf nitrogen maps of the experimental plots, are shown in Fig. 4. The different experimental plots can be visually discriminated according to their leaf $\mathrm{N}$ levels. They correspond well to the nitrogen treatments that were applied to each plot.
Fig. 5 shows the $\mathrm{N}$ treatment that was applied on each plot, and the corresponding leaf $\mathrm{N}$ content from the laboratory.

The predictive values of leaf $\mathrm{N}$ content were $3.0-6.6 \%$ from Fig.4. The laboratory measurement values were 3.6-5.9\% from Fig.5. Comparison the two maps shows that the use of predictive model based on TCARI/OSAVI using AISA airborne hyperspectral data was proved to have added value in evaluating $\mathrm{N}$ levels in potatoes fields.

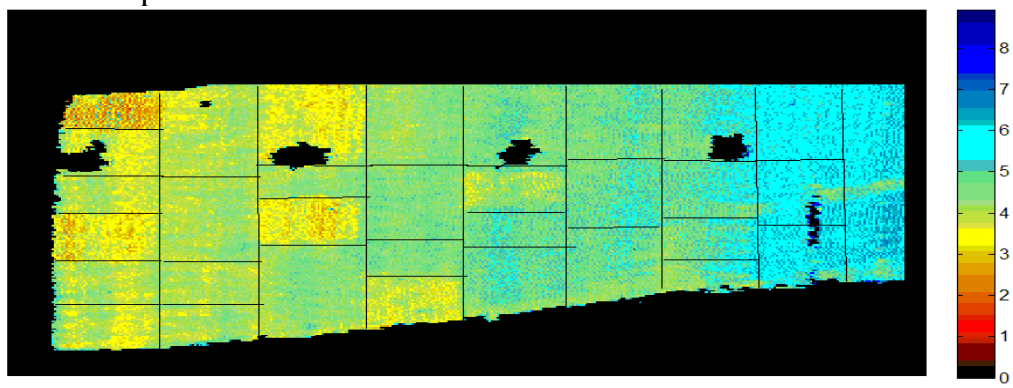

Figure 4. Map of leaf $\mathrm{N}$ status determined from ASIA hyperspectral image of April 11, 2008 using predictive equation of the ratio TCATI/OSAVI 


\begin{tabular}{|c|c|c|c|c|c|c|c|}
\hline $\begin{array}{l}3.82 \% \\
(\mathrm{~T} 0-2)\end{array}$ & $\begin{array}{c}4 \\
5.08 \%+\end{array}$ & $4.52 \%$ & 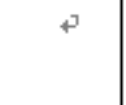 & $4.13 \%+$ & $4.61 \%$ & $\begin{array}{c}4 \\
5.37 \%\end{array}$ & $5.89 \%$ \\
\hline $\begin{array}{l}5.49 \% \\
(T 42)\end{array}$ & $(\mathrm{T} 6-3)+$ & $(\mathrm{T} 1-3)+$ & & {$[2-3)+4$} & $(T 44)$ & $(T 6-4)$ & {$[5-2)$} \\
\hline $\begin{array}{l}4.88 \%+ \\
(\mathrm{T} 2-2)\end{array}$ & $\begin{array}{c}4 \\
4.39 \%+\end{array}$ & 5 & $\begin{array}{c}4 \\
4.60 \%\end{array}$ & $\begin{array}{l}4.15 \% \\
\text { (T1-4) }\end{array}$ & $4.11 \%$ & $\begin{array}{c}4 \\
4.19 \%\end{array}$ & 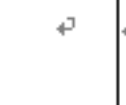 \\
\hline $\begin{array}{l}4.12 \%+ \\
(T 1-2)\end{array}$ & $\begin{array}{c}\text { (T3-3) } \\
-\end{array}$ & $\begin{array}{l}3.59 \%+ \\
(\mathrm{T} 0-3)\end{array}$ & $(T 43)+$ & 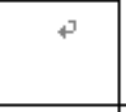 & $(T 2-4)$ & (T3-4) & \\
\hline $\begin{array}{l}4.73 \%+ \\
(T 6-2)\end{array}$ & 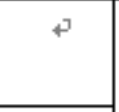 & $\begin{array}{c}4 \\
4.80 \%+\end{array}$ & 7 & $\begin{array}{c}4 \\
4.52 \%+\end{array}$ & $\begin{array}{c}4 \\
4.92 \%\end{array}$ & $\begin{array}{l}4.18 \% \\
(\mathrm{~T} 0-4)\end{array}$ & $\begin{array}{c}4 \\
5.48 \%+\end{array}$ \\
\hline $\begin{array}{l}4.71 \% \\
(\mathrm{~T} 3-2)\end{array}$ & $\begin{array}{l}4.96 \% \\
(\mathrm{~T} 2-1)\end{array}$ & $(\mathrm{T} 41)+$ & $\begin{array}{l}3.84 \% \\
(\mathrm{~T} 0-1)\end{array}$ & $(T 6-1)+$ & $(T 3-1)$ & $\begin{array}{l}4.25 \% \\
\text { (T1-1) }\end{array}$ & $(T 5-1)+$ \\
\hline
\end{tabular}

Figure 5. Map of $\mathrm{N}$ treatment and corresponding mean leaf $\mathrm{N}$ content in each plot of 2008

\section{CONCLUSIONS}

Based on the use of a wide range of potato data [2 years, five $\mathrm{N}$ treatments (T0-T4) in 2007, seven $\mathrm{N}$ treatments (T0-T6) in 2008], the comparison of two spectral indices (TCARI, TCARI/OSAVI) for airborne hyperspectral data. The ratio TCARI/OSAVI resulted in stronger correlations than TCARI with leaf $\mathrm{N}$ for canopy spectral reflectance. The estimation model from the ratio TCARI/OSAVI was applied to all the potato pixels of the airborne image. The values of the leaf $\mathrm{N}$ distribution map ranged from $3.0 \%$ to $6.6 \%$, which was quite consistent with those of field measurements from $3.6 \%$ to $5.9 \%$. So the present study shows a great potential for estimating potato leaf $\mathrm{N}$ using AISA airborne hyperspectral data.

\section{REFERENCES}

[1] National Potato Council (NPC). Potato statistical yearbook, 2006-2007. National Potato Council, Washington, DC. 2006, 82 pp.

[2] Dar, Z.. Potato crop protocol. Ministry of Agriculture Extension Service, 2002,Bet Dagan, Israel.

[3] Errebhi, M., Rosen, C. J., Gupta, S. C., \& Birong, D. E.. Potato yield response and nitrate leaching as influenced by nitrogen management. Agronomy Journal, 90, 1996, pp. 10-15.

[4] Al-Abbas, A. H., Barr, R., Hall, J. D., Crane, F. L., \& Baumgardner, M. F. . Spectra of normal and nutrient-deficient maize leaves. Agronomy Journal, 66, 1974, pp. 16-20.

[5] Botha, E. J., Zebarth, B. J., \& Leblon, B.. Non-destructive estimation of potato leaf chlorophyll and protein contents from hyperspectral measurements using the PROSPECT radiative transfer model. Canadian Journal of Plant Science, 86, 2006, pp. 279-291.

[6] Gitelson, A. A., Gritz, Y., \& Merzlyak, M. N.. Relationships between leaf chlorophyll content and spectral reflectance and algorithms for non-destructive chlorophyll assessment in higher plant leaves. Journal of Plant Physiology, 160, 2003, pp. 271-282.

[7] Thomas, J. R., \& Gausman, H. W. Leaf reflectance vs. leaf chlorophyll and carotenoid concentrations for eight crops. Agronomy
Journal, 69, 1997, pp. 799-802.

[8] Zakaluk, R., \& Ranjan, R. S. . Artificial neural network modelling of leaf water potential for potatoes using RGB digital images: a greenhouse study. Potato Research, 49, 2007, pp. 255-272.

[9] Haboudane, D., Miller, J. R., Tremblay, N., Zarco-Tejada, P. J., \& Dextraze, L. . Integrated narrow-band vegetation indices for prediction of crop chlorophyll content for application to precision agriculture. Remote Sensing of Environment, 81, 2002, pp. 416-426.

[10] Gates, D. M., Keegan, H. J., Schleter, J. C., \& Weidner, V. R.. Spectral properties of plants. Applied Optics, 4, 1965, pp. 11-20.

[11] Jain, N., Ray, S. S., Singh, J. P., \& Panigrahy, S.. Use of hyperspectral data to assess the effects of different nitrogen applications on a potato crop. Precision Agriculture, 8, 2007, pp. 225-239.

[12] Chen, P, F., Haboudane, D., Tremblay, N., et al. . New spectral indicator assessing the efficiency of crop nitrogen treatment in corn and wheat. Remote Sensing of Environment, 2010, pp. 1987-1997.

[13] Ryu, C,S., Suguri, M., Umeda, M.. Making nitrogen contents model using hyperspectral remote sensing and estimation nitrogen contents by nitrogen content model. (in Japanese with English abstract). Journal of JSAM, 67(6), 2005, pp. 47-54.

[14] Ryu, C,S., Suguri, M., Umeda, M.. Mode for predicting the nitrogen content of rice at panicle initiation stage using data from airborne hyperspectral remote sensing. Precision Agriculture, 2009, pp. 465-475.

[15] Alchanatis, V., Schmilovitch, Z., \& M. Meron . In-field assessment of single leaf nitrogen status by spectral reflectance measurements. Precision Agriculture, 6, 2005, pp. 25-39.

[16] Cohen, Y., Alchanatis, V., Zusman, Y., et al.. Leaf nitrogen estimation in potato based on spectral data and on simulated bands of the VEN $\mu$ S satellite. Precision Agriculture, 11, 2010, pp. 520-537.

[17] Kjeldahl, J . Neue method zur bestimmung des stickstoffs in oranischen korpern.. Z Anal Chem, 22, 1883, pp. 366-382.

[18] Zarco-Tejada, P. J., Berjon, A., Lopez-Lozano, R., Miller, J. R., Martin, P., Cachorro, V., Gonzalez, M. R., \& de Frutos, A. Assessing vineyard condition with hyperspectral indices: leaf and canopy reflectance simulation in a row-structured discontinuous canopy. Remote Sensing of Environment, 99, 2005, pp. 271-287 